\title{
Validade de conteúdo das provas de um curso de compreensão oral para fins acadêmicos: relato de uma experiência
}

\section{Content validity of tests applied in an oral comprehension course for academic purposes: an experience report}

\author{
Gladys QUEVEDO-CAMARGO* \\ Gabriela Martins SANTOS**
}

\begin{abstract}
RESUMO: Neste relato de experiência, fazemos a análise da validade de conteúdo (GREEN, 2014) das provas aplicadas em um curso de Inglês para Fins Acadêmicos com foco na compreensão oral no Programa Idiomas sem Fronteiras - IsF. O objetivo foi verificar o alinhamento entre o plano de ensino e as provas. As categorias de análise foram as micro e macroabilidades da compreensão oral conforme Brown (2004; 2007). Foram aplicados questionários aos alunos para verificar sua percepção quanto à clareza das questões e ao grau de dificuldade dos áudios. Os resultados indicaram que a primeira prova apresenta validade de conteúdo satisfatória, dois áudios considerados não muito difíceis e questões que não causaram problemas de compreensão. Na segunda, a validade de conteúdo foi parcial $(60 \%)$ e o julgamento quanto à dificuldade do áudio e à clareza das questões coincidiu com o expresso para a primeira. A terceira prova foi considerada portadora de validade de conteúdo, embora tenha sido complexo fazer tal verificação porque não havia correspondência explícita entre o plano de ensino e a rubrica das questões. Quanto à clareza das questões, houve a mesma percepção das provas anteriores e o áudio foi o que mais alunos consideraram difícil, levandonos a refletir sobre possíveis motivos para tal.
\end{abstract}

PALAVRAS-CHAVE: Validade de conteúdo. Compreensão oral. Inglês para fins acadêmicos - IFA. Idiomas sem Fronteiras IsF.

\begin{abstract}
In this report, we analyze the content validity (GREEN, 2014) of tests applied in an English for Academic Purposes course focusing on oral comprehension taught at the Languages without Borders Program. The aim was to verify the alignment between the teaching plan and the tests. The categories for analysis were the micro and macroskills according to Brown (2004; 2007). Questionnaires were used to collect students' perceptions about the questions' clarity and the audio's level of difficulty. The results indicated that the first test presented satisfactory content valididy, two not very difficult audios and questions that did not pose comprehension problems. In the second test, content validity was partial $(60 \%)$ and judgment concerning question clarity and audio difficulty were the same as before. As for the third test, it was considered content valid, though it was complex to verify that because there was no explicit correspondence between the teaching plan and the question rubrics. In relation to the clarity of the questions, it was the same as for the previous tests, and the audio was the one students considered the most difficult, leading us to reflections on possible reasons for that.
\end{abstract}

KEYWORDS: Content validity. Oral comprehension. English for academic purposes - EAP. Languages without Borders.

\footnotetext{
* Doutora em Estudos da Linguagem; docente do Departamento de Línguas Estrangeiras e Tradução do Instituto de Letras da Universidade de Brasília - UnB. https://orcid.org/0000-0002-4802-5296. E-mail: gladys@unb.br ** Aluna do curso de graduação em Letras-Inglês Licenciatura da Universidade de Brasília - UnB. https://orcid.org/0000-0002-9144-1455. E-mail: gabrielamartins0102@gmail.com
} 


\section{Introdução}

O Programa Idiomas sem Fronteiras (IsF) tem como seu principal objetivo a internacionalização do Ensino Superior brasileiro, e a contribuição para a formação préserviço de alunos de Letras/Licenciatura é uma das suas principais características (ABREU-ELIMA et al., 2020). Com o apoio e a supervisão dos coordenadores pedagógicos, os alunosprofessores (licenciandos) do IsF têm a oportunidade de elaborar cursos voltados às habilidades necessárias no meio acadêmico, de preparar materiais para esses cursos e de ministrar as aulas em diversos idiomas, de acordo com cada Instituição de Ensino Superior. O público-alvo desses cursos são membros das comunidades das universidades conveniadas: docentes e discentes dos cursos de graduação e pós-graduação, servidores técnicos e terceirizados.

Na Universidade de Brasília (UnB), o IsF-inglês apresentou a particularidade de se caracterizar como um locus de iniciação à pesquisa para os professores-docentes. A partir desse contexto, o presente artigo relata uma pesquisa cujo propósito foi analisar a validade das provas aplicadas em um dos cursos oferecidos pelo IsF-Inglês no segundo semestre de 2019, chamado 'Compreensão Oral: Palestras e Aulas B1/16h' por meio da verificação do alinhamento (total, parcial ou nulo) entre essas provas e o plano de ensino. Esse curso, que será detalhado adiante, concentra-se, como o próprio nome indica, na compreensão oral em contexto acadêmico. Justamente devido a essas características específicas, surgiram indagações a respeito das provas elaboradas pela equipe para verificar o progresso dos alunos. Estariam elas avaliando adequadamente os conteúdos e as técnicas trabalhadas em classe? Os áudios utilizados estariam apropriados? Essas e outras perguntas motivaram este estudo pela primeira autora, coordenadora pedagógica do IsF-Inglês, e pela segunda, aluna-professora e licencianda.

Para este relato, apresentamos brevemente, na sequência, o embasamento teórico que norteou a pesquisa, seu desenho metodológico e as análises desenvolvidas. Finalizamos com reflexões acerca do processo avaliativo e seus desafios em um curso dessa natureza.

\section{Pressupostos teóricos}

Este trabalho apoiou-se em princípios fundamentais da avaliação (de línguas) e aspectos relativos ao ensino, à aprendizagem e à avaliação da compreensão oral em língua 
inglesa (listening). Iniciamos com os três princípios básicos da avaliação (de línguas), a saber, validade, confiabilidade e praticidade.

Segundo Brown (2007), a validade é um conceito que diz respeito ao quanto uma prova avalia bem o que se propõe a avaliar. Diversos autores, porém, não acreditam que a validade seja uma qualidade inerente ao instrumento de avaliação em si, mas que está relacionada ao uso que se faz dele (RETORTA; MAROCHI, 2018). A literatura menciona diferentes tipos de validade, como a validade de construto, a validade de face e a validade de conteúdo, por exemplo. É sobre este último tipo que nos concentramos neste trabalho: existe validade de conteúdo quando uma prova se constitui em uma amostra representativa das habilidades ou conteúdos trabalhados em um curso. De acordo com Green (2014, p. 78), “[i]dealmente, o material incluído em uma avaliação deveria representar toda a gama de conhecimentos, competências ou habilidades que a avaliação intenciona cobrir" ${ }^{\text {. }}$. Portanto, para analisar se uma prova apresenta validade de conteúdo ou não, temos que ter estabelecidas, de antemão, as habilidades e os conteúdos a serem cobrados na prova (RETORTA; MAROCHI, 2018). No caso deste relato, o plano de ensino do curso foi nossa matriz de habilidades e conteúdos preestabelecidos com a qual comparamos as provas aplicadas.

O segundo princípio é a confiabilidade de uma prova. Para Brown (2007, p. 447), "uma prova confiável é consistente e estável", ou seja, há ausência de flutuações com relação às condições em que se encontram os alunos , à atribuição do escore, à administração do teste, e ao teste propriamente dito (BROWN, 2004). Green (2014) também menciona, entre outras características de uma prova confiável, clareza e não-ambiguidade das instruções ou rubricas, padronização das condições da sua administração, e controle sobre como a avaliação é corrigida. ${ }^{3}$ Esses aspectos foram considerados nas análises que apresentaremos adiante.

O terceiro e último conceito é a praticalidade. Um teste é considerado prático quando sua elaboração, aplicação e correção encontram-se dentro dos limites de tempo e dos recursos disponíveis, "além de ter ótima relação custo-benefício" (RETORTA; MAROCHI, 2018, p. 69). A praticalidade das provas do curso analisado também foi verificada e será abordada em breve.

\footnotetext{
${ }^{1}$ No original: Ideally, the material included in an assessment should represent the full range of knowledge, skills or abilities that the assessment is intended to cover. (Nossa tradução, assim como todas as demais neste artigo.)

${ }^{2}$ No original: A reliable test is consistent and dependable.

${ }^{3}$ Para mais características de confiabilidade da avaliação de línguas, ver Green (2014, p. 73-74).
} 
Com relação ao ensino, à aprendizagem e à avaliação da compreensão oral em língua inglesa, orientamo-nos pela classificação de micro e macro-habilidades de Brown (2004; 2007). De acordo com o autor, as micro-habilidades se referem ao nível da sentença e estão relacionadas a técnicas bottom-up, nas quais a compreensão é desenvolvida a partir das unidades menores da língua (de baixo para cima), como os sons, as palavras, a entonação, e as estruturas gramaticais, e as macro-habilidades ao nível do discurso, relativas a técnicas topdown, que mobilizam elementos mais amplos como, por exemplo, o conhecimento que o ouvinte já possui sobre o tema.

Por fim, o gênero textual utilizado no curso em análise - que corresponde a palestras curtas ou monólogos entre 3:00 e 9:00 minutos de duração - requer, segundo Brown (2007), uma compreensão oral seletiva. Para o autor, nesse tipo de compreensão oral, o aluno não precisa "processar tudo que foi dito, mas sim escanear o material seletivamente [...]. $\mathrm{O}$ propósito de tal desempenho não é buscar significados globais ou gerais, necessariamente, mas ser capaz de encontrar informações importantes em meio a uma série de informações potencialmente distratoras [...]" (BROWN, 2007, p. 309) ${ }^{4}$.

Na sequência, relatamos a metodologia utilizada neste estudo.

\section{Metodologia}

Nesta seção apresentamos nosso objetivo de pesquisa, seguido pelo detalhamento do curso ‘Compreensão Oral: Palestras e Aulas B1/16h' e das provas utilizadas. Apresentamos também os participantes das duas turmas envolvidas neste estudo e algumas informações coletadas junto a eles por meio de questionários.

\section{$3.1 \mathrm{O}$ objetivo da pesquisa}

O IsF Nacional possui um extenso catálogo de cursos (BRAGA et al, 2020), a partir do qual cada Universidade conveniada seleciona os cursos que lhe convêm de acordo com sua realidade e elabora seu plano de ensino e suas provas. O curso 'Compreensão Oral: Palestras e Aulas B1/16h' já havia sido ofertado diversas vezes pelo IsF-Inglês/UnB, sempre com boa procura pela comunidade acadêmica.

\footnotetext{
${ }^{4}$ No original: [...] the task of the student is not to process everyting that was said, but rather to scan the material selectively [...]. The purpose of such performance is not to look for global or general meanings, necessarily, but to be able to find important information in a field of potentially distracting information.
} 
No IsF-Inglês/UnB, tanto os planos quanto as provas foram elaborados pela própria equipe em regime de divisão de trabalho. Porém, durante as reuniões pedagógicas realizadas entre os alunos-professores e a coordenação pedagógica, a questão do alinhamento entre o que era ministrado e o que as provas traziam era um assunto recorrente de questionamento. Diante disso, no início do segundo semestre de 2019, desenhamos este estudo com a principal finalidade de verificar se as provas desse curso específico estavam alinhadas ao plano de aula sendo utilizado. Para realizar essa verificação, fizemos uma análise documental de fontes primárias escritas elaboradas por terceiros ${ }^{5}$ (MARCONI; LAKATOS, 2003), a saber, o plano de ensino e as três provas do curso. Além disso, em duas turmas em que o curso foi ministrado, coletamos as percepções dos alunos em relação às provas por meio de questionários, sobre os quais discorreremos adiante.

\section{$3.2 \mathrm{O}$ curso e as três provas}

O curso 'Compreensão Oral: Palestras e Aulas B1/16h', cujo plano de ensino vemos no Quadro 1, possui, como já indicamos, uma curta duração de dezesseis horas, que podem ser distribuídas de duas maneiras: duas vezes por semana com aulas de duas horas cada, ou uma vez por semana com uma aula de quatro horas de duração.

Devido à carga horária reduzida de diversos cursos do IsF, foram elaboradas provas objetivas, sempre com o mesmo formato: 10 questões V/F. No caso desse curso especificamente, as provas eram disponibilizadas aos alunos via GoogleForms em sala de aula no dia da avaliação ${ }^{6}$, e o áudio poderia ser tocado duas vezes. Como mostra o Quadro 1, temos a aplicação das provas nas aulas 8,12 e 16 .

Quadro 1 - Plano de ensino do curso Compreensão Oral: Palestras e Aulas B1/16h do IsF.

\begin{tabular}{cl} 
Horas & \multicolumn{1}{c}{ Conteúdos/Técnicas } \\
$\mathbf{1 - 2}$ & a estrutura de uma palestra ou aula; diferenças entre aulas e palestras; sequence words \\
$\mathbf{3 - 4}$ & identificar ideias principais; identificar detalhes; identificar informações específicas \\
$\mathbf{5 - 6}$ & identificar explicações; identificar exemplos \\
$\mathbf{7 - 8}$ & tomar notas; resumir; prova 1 \\
$\mathbf{9 - 1 0}$ & identificar comparação e contraste
\end{tabular}

\footnotetext{
${ }^{5}$ Sob a supervisão da primeira autora deste artigo, a segunda autora, graduanda em Letras-Inglês Licenciatura pela Universidade de Brasília, foi responsável por ministrar duas turmas do curso 'Compreensão Oral: Palestras e Aulas B1/16h'. Atuou no Programa IsF-Inglês/UnB durante todo o ano de 2019 ministrando esse e diversos outros cursos. Não participou da elaboração do plano de ensino nem das provas do curso porque tais materiais já estavam prontos quando do seu ingresso no Programa.

${ }^{6}$ Tal viabilização fazia uso da rede wifi da universidade.
} 
11-12 identificar causa e efeito; prova 2

13-14 identificar argumentação

15-16 identificar argumentação; prova 3

Fonte: Elaborado pelas autoras.

O Quadro 2 apresenta as micro e macroabilidades que constam no material do curso 'Compreensão Oral: Palestras e Aulas B1/16h' do IsF, elaborado pela equipe com base em Scanlon (2010), Freire e Jones (2011), Craven e Sherman (2010), Bohlke e Lockwood (2013), e Boyle e Kisslinger (2013).

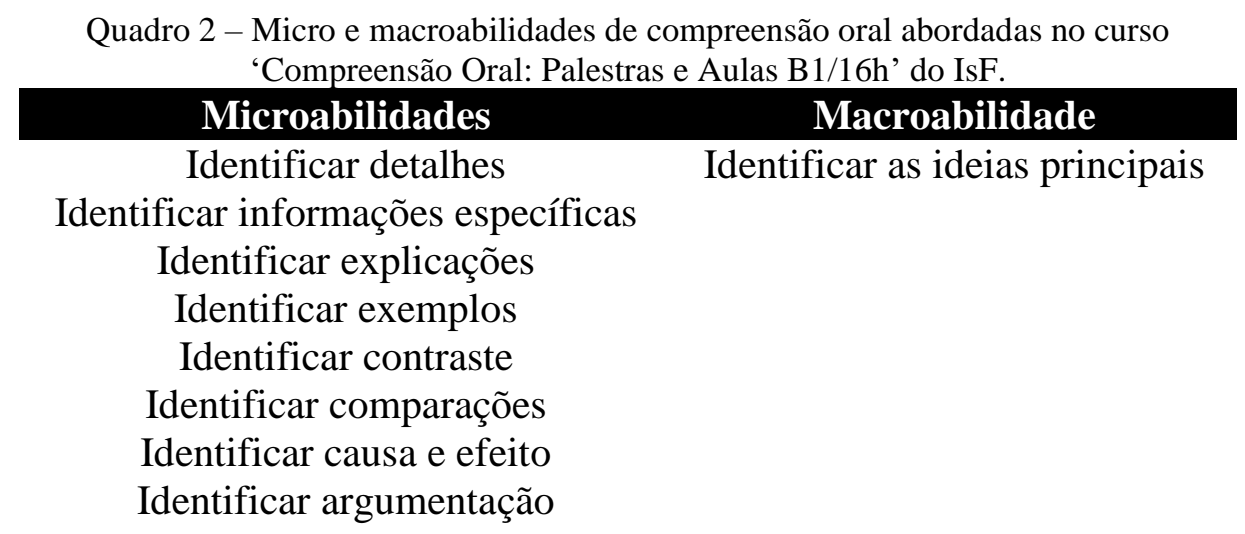

Fonte: Elaborado pelas autoras.

Esse quadro deixa claro que o curso se concentra bastante em micro-habilidades, justamente por intencionar dar suporte a alunos com pouca familiaridade com essa habilidade tão necessária no ambiente acadêmico: a compreensão oral. Essa opção vai ao encontro do que afirma Brown (2007) sobre o escaneamento seletivo, mencionado na seção anterior.

Em termos de atividades propostas aos alunos para desenvolver as micro e macrohabilidades apresentadas, o curso apresenta exercícios de respostas curtas do tipo cloze (preenchimento de lacunas em um texto), questões de verdadeiro ou falso (V/F), e exercícios de respostas um pouco mais longas, como tomada de notas e resumos, conforme Ur (1996).

Com relação ao sistema avaliativo previsto para o curso, é importante ressaltar que as provas são as únicas formas de avaliação, uma vez que não estão previstas atividades de avaliação formativa para compor a nota final dos estudantes, ou seja, não se avalia o aluno durante o processo de aprendizagem. Sendo assim, o curso apresenta um sistema que se apoia exclusivamente na avaliação somativa ${ }^{7}$.

\footnotetext{
${ }^{7}$ A respeito dos conceitos de avaliação formativa e somativa, ver por exemplo Brown $(2004 ; 2007)$.
} 


\subsection{Os participantes}

Com relação aos participantes nas duas ofertas do curso no segundo semestre de 2019, cinco alunos fizeram o curso todo na primeira oferta, e oito na segunda. Os cursos desses alunos são apresentados no quadro a seguir.

Quadro 3 - Perfil dos participantes do curso 'Compreensão Oral: Palestras e Aulas B1/16h' - 2º semestre 2019.

\begin{tabular}{|c|c|c|}
\hline & $\mathbf{N}^{0} \cdot$ alunos & Cursos de origem \\
\hline $1^{a}$ turma & 5 & $\begin{array}{l}\text { - Pedagogia } \\
\text { - Comunicação Social - Audiovisual. } \\
\text { - Serviço Social } \\
\text { - Doutorado em Tecnologias Química e Biológica } \\
\text { - Letras - Português }\end{array}$ \\
\hline $2^{\mathrm{a}}$ turma & 8 & $\begin{array}{l}\text { - Professor(a) universitário(a) } \\
\text { - Gestão Ambiental } \\
\text { - Artes Visuais } \\
\text { - Ciências Contábeis } \\
\text { - História } \\
\text { - Mestrado em Política Social } \\
\text { - Engenharia automotiva } \\
\text { - Pedagogia }\end{array}$ \\
\hline
\end{tabular}

Fonte: Elaborado pelas autoras.

Portanto, computando as duas turmas, havia dez alunos de graduação, dois alunos de pós-graduação e um professor universitário.

\subsection{Os questionários}

Para coletar a percepção dos alunos com relação às provas, utilizamos quatro questionários feitos também no Google Forms com questões de múltipla escolha e perguntas abertas, conforme detalhado no quadro a seguir.

Quadro 4-Questionários aplicados aos alunos do curso

'Compreensão Oral: Palestras e Aulas/16h'.

\begin{tabular}{|c|c|c|c|}
\hline Questionário & Aplicação & No. Questões & Objetivo \\
\hline Inicial (QI) & Antes do curso & 8 (7 fechadas; 1 aberta) & $\begin{array}{c}\text { Dados gerais dos alunos e } \\
\text { experiência prévia com provas } \\
\text { de compreensão oral }\end{array}$ \\
\hline 1 (Q1) & Após Prova 1 & 4 (3 fechadas; 1 aberta) & Percepções sobre a Prova 1 \\
\hline $2(\mathrm{Q} 2)$ & Após Prova 2 & 3 (2 fechadas; 1 aberta $)$ & Percepções sobre a Prova 2 \\
\hline $3(\mathrm{Q} 3)$ & Após Prova 3 & 9 (todas fechadas) & Percepções sobre a Prova 3 \\
\hline
\end{tabular}

Fonte: Elaborado pelas autoras. 
O primeiro questionário, que denominamos Questionário Inicial (QI) e reproduzimos na sequência, foi enviado por e-mail antes mesmo do primeiro contato com os alunos em classe, e o objetivo foi coletar dados gerais sobre eles, assim como suas impressões sobre as provas de compreensão oral em inglês que já haviam realizado.

Quadro 5 - Reprodução do Questionário Inicial (QI) aplicado aos alunos do curso 'Compreensão Oral: Palestras e Aulas/16h'.

1.Você já estudou em um curso de inglês?

( ) Sim, em um curso particular.

( ) Nunca estudei em um curso de inglês.

( ) Sim, em um curso gratuito.

( ) Outro:

2. Quando se trata do aprendizado do inglês, a habilidade de escutar e entender o que foi dito é a mais difícil.
( ) Concordo muito.
( ) Neutro.
( ) Discordo.
( ) Concordo.
( ) Discordo muito.

3. Nas avaliações de compreensão oral que tive, o conteúdo das provas (áudios, perguntas) parecia ser mais difícil do que o conteúdo passado em sala de aula.
( ) Concordo muito.
( ) Neutro.
( ) Discordo.
( ) Concordo.
( ) Discordo muito.

4. Sinto que me saio melhor nas atividades feitas em sala do que nas avaliações.
( ) Concordo muito.
( ) Neutro.
( ) Discordo.
( ) Concordo.
( ) Discordo muito.

5. Já me perdi em uma prova de compreensão oral e não consegui identificar em qual questão eu estava.
( ) Concordo muito.
( ) Neutro.
( ) Discordo.
( ) Concordo.
( ) Discordo muito.

6. Já senti, ao responder uma prova de inglês, que o que estava sendo avaliado era algo ACIMA do meu nível de inglês.
( ) Concordo muito.
( ) Neutro.
( ) Discordo.
( ) Concordo.
( ) Discordo muito.

7. Já senti, ao responder uma prova de inglês, que o que estava sendo avaliado era algo ABAIXO do meu nível de inglês.
( ) Concordo muito.
( ) Neutro.
( ) Discordo.
( ) Concordo.
( ) Discordo muito.

8. O que eu acho mais difícil em uma prova de compreensão oral é

Fonte: Elaborado pelas autoras. 
Os Questionários 1, 2 e 3 objetivaram coletar as impressões dos estudantes em relação a cada prova aplicada no curso. O primeiro questionário (Q1) apresentava quatro perguntas, como mostra o quadro a seguir.

Quadro 6 - Reprodução do Questionário 1 (Q1) aplicado aos alunos do curso 'Compreensão Oral: Palestras e Aulas/16h' após a primeira prova.

1. Qual nível de dificuldade você daria para o primeiro áudio da prova?
( ) Muito difícil.
( ) Mediano.
( ) Fácil.
( ) Difícil.
( ) Muito fácil.

2. Qual nível de dificuldade você daria para o segundo áudio da prova?
( ) Muito difícil.
( ) Mediano.
( ) Fácil.
( ) Difícil.
( ) Muito fácil.

3. Qual nível de dificuldade você daria para a clareza das PERGUNTAS?

( ) Muito difícil. Extremamente complicadas.

( ) Difícil. Não estavam claras.

( ) Mediano. Não vi grandes problemas em relação às perguntas.

( ) Fácil. Pude compreende-las tranquilamente.

( ) Muito fácil. Extremamente claras.

4. Caso você tenha respondido difícil/muito difícil em alguma questão acima, responda: quais elementos contribuíram para essa dificuldade? (ex: áudios, vocabulário, sotaque, rapidez etc.)

\section{Fonte: Elaborado pelas autoras.}

Nos dois últimos - Q2 e Q3 - não há perguntas sobre uma segunda passagem porque as provas continham apenas um áudio cada.

Quadro 7 - Reprodução do Questionário 2 (Q2) aplicado aos alunos do curso

'Compreensão Oral: Palestras e Aulas/16h' após a segunda prova.

1. Qual nível de dificuldade você daria para o áudio da prova?
( ) Muito difícil.
( ) Mediano.
( ) Fácil.
( ) Difícil.
( ) Muito fácil.

2. Qual nível de dificuldade você daria para a clareza das PERGUNTAS?

( ) Muito difícil. Extremamente complicadas.

( ) Difícil. Não estavam claras.

( ) Mediano. Não vi grandes problemas em relação às perguntas.

( ) Fácil. Pude compreende-las tranquilamente.

( ) Muito fácil. Extremamente claras.

3. Caso você tenha respondido difícil/muito difícil em alguma questão acima, responda: quais elementos contribuíram para essa dificuldade? (ex: áudios, vocabulário, sotaque, rapidez etc.)

Fonte: Elaborado pelas autoras 
E o Q3 foi expandido para coletar algumas reflexões acerca do curso, como mostra o quadro abaixo.

Quadro 8 - Reprodução do Questionário 3 (Q3) aplicado aos alunos do curso 'Compreensão Oral: Palestras e Aulas/16h' após a terceira prova.

1. Qual nível de dificuldade você daria para o áudio da prova?
( ) Muito difícil.
( ) Mediano.
( ) Fácil.
( ) Difícil.
( ) Muito fácil.

2. Qual nível de dificuldade você daria para a clareza das PERGUNTAS?

( ) Muito difícil. Extremamente complicadas.

( ) Difícil. Não estavam claras.

( ) Mediano. Não vi grandes problemas em relação às perguntas.

( ) Fácil. Pude compreende-las tranquilamente.

( ) Muito fácil. Extremamente claras.

3 Caso você tenha respondido difícil/muito difícil em alguma questão acima, responda: quais elementos contribuíram para essa dificuldade? (ex: áudios, vocabulário, sotaque, rapidez etc.)

4. Na sua opinião, a prova foi desafiadora?

( ) Sim, a avaliação demandou muito esforço.

( ) Não, não precisei me esforçar muito para responder às questões.

( ) Talvez. A avaliação em si não foi muito desafiadora.

\section{REFLEXÕES ACERCA DO CURSO}

5. Na sua opinião, as avaliações tiveram sucesso ao tentar abarcar os conteúdos passados ao longo do curso?

( ) Sim, grande parte do que foi passado está refletido nas avaliações.

( ) Não, não consegui estabelecer a relação do conteúdo do curso com o conteúdo das avaliações.

( ) Talvez. Consegui identificar algumas coisas que foram estudadas, mas acho que poderia melhorar.

6. Você acha que as provas estão em um nível um pouco acima do seu nível de inglês?
( ) Sim
( ) Não
( ) Talvez

7. Você acha que as provas estão em um nível um pouco abaixo do seu nível de inglês?
( ) Sim
( ) Não
( ) Talvez

(perguntas feitas somente na $2^{\mathrm{a}}$ oferta do curso)

8. Na sua opinião, o número ideal de provas nesse curso seria...
( ) uma prova
( ) duas provas
( ) três provas
( ) quatro provas

9. Todas as questões das provas do curso foram de verdadeiro ou falso. Na sua opinião, o formato mais adequado de perguntas é:

( ) Verdadeiro ou falso

( ) Múltipla escolha

( ) Preencher os espaço (fill-in-the-gaps) 
( ) Acho que poderia haver uma mescla de opções.

Fonte: Elaborado pelas autoras.

Na próxima seção, apresentamos a análise das provas utilizadas no curso.

\section{Análise das provas}

Nesta seção, analisamos os planos gerais das três provas $^{8}$ do curso e os confrontamos com o plano de ensino para verificar possíveis alinhamentos.

\section{Prova 1}

A primeira prova, aplicada na oitava hora do curso, é composta por dois áudios do gênero palestra e dez questões. O primeiro áudio chama-se Automobiles, tem 05:41 minutos de duração e há seis questões elaboradas a partir dele; o segundo é intitulado First Impressions, tem 03:27 minutos de duração e há quatro questões elaboradas a partir dele. Todas são do tipo V/F. No quadro a seguir, temos uma visão detalhada da técnica mobilizada em cada questão da prova.

Quadro 9 - Técnicas mobilizadas pelas questões da Prova 1.

\begin{tabular}{|l|cl|}
\multicolumn{1}{c|}{} & Questão & \multicolumn{1}{c|}{ Técnica } \\
\hline & 1 & Informação específica \\
Áudio & 2 & Detalhe/Exemplo \\
Automobiles & 3 & Detalhe/Exemplo \\
& 4 & Detalhe/Explicação \\
& 5 & Detalhe/Fato \\
& 6 & Detalhe/Fato \\
\hline \multirow{3}{*}{ Áudio } & 7 & Detalhe/Explicação \\
First Impressions & 8 & Detalhe/Explicação \\
& 9 & Detalhe/Explicação \\
\hline
\end{tabular}

Fonte: Elaborado pelas autoras.

Voltando ao conteúdo e às técnicas trabalhadas nas sete primeiras horas do curso antes da primeira prova, temos o quadro a seguir, no qual destacamos as técnicas contempladas na Prova 1.

\begin{tabular}{|c|c|}
\hline $\begin{array}{l}\text { Hora } \\
\text { S }\end{array}$ & Conteúdos/Técnicas \\
\hline
\end{tabular}

\footnotetext{
${ }^{8}$ As provas não serão apresentadas aqui para resguardar a confidencialidade do material do IsF-Inglês/UnB.
} 


\section{3-4 identificar ideias principais; identificar detalhes; identificar informações específicas \\ 5-6 identificar explicações; identificar exemplos \\ 7-8 tomar notas; resumir; prova 1}

Fonte: Elaborado pelas autoras.

Esse quadro nos mostra que três técnicas foram contempladas na primeira prova: identificação da ideia principal, identificação de informações específicas e detalhes, que aparecem nas palestras na forma de fatos, exemplos e explicações. Observamos que a Prova 1 dá grande ênfase à identificação de detalhes, pois apresenta oito questões que avaliam essa técnica, enquanto há somente uma para identificação de informações específicas e uma para identificação da ideia principal.

Em termos de validade de conteúdo, parece-nos que há alinhamento praticamente total, uma vez que a prova contempla a macroabilidade 'identificar ideias principais' e as demais microabilidades abordadas nas aulas 3 a 6 . Nesse sentido, essa prova poderia ser considerada $100 \%$ válida. Além disso, essa maior ênfase em detalhes estaria em consonância com a afirmação de Brown (2007) apresentada anteriormente, para quem monólogos ou palestras requerem compreensão oral seletiva.

Vejamos nos gráficos a seguir, a percepção dos alunos com relação à dificuldade dos dois áudios e à clareza das questões da Prova 1.

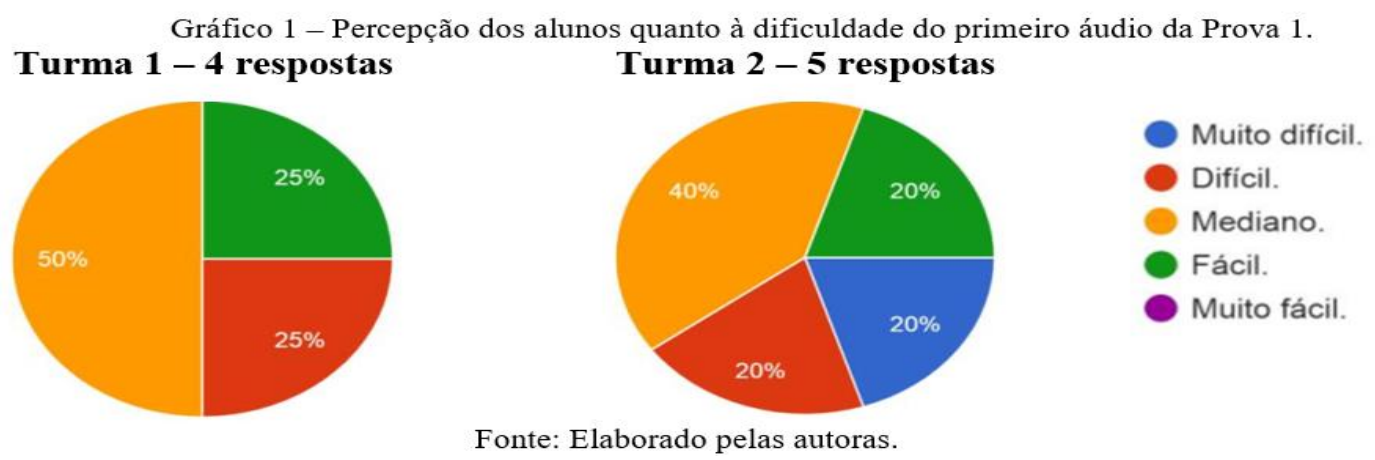

Esse gráfico indica que, de acordo com a percepção dos alunos das duas turmas, a dificuldade do primeiro áudio se configura como majoritariamente mediana. Houve um certo equilíbrio entre o julgamento difícil e fácil, e poucos acharam o áudio muito difícil. 
Gráfico 2 - Percepção dos alunos quanto à dificuldade do segundo áudio da Prova 1 .

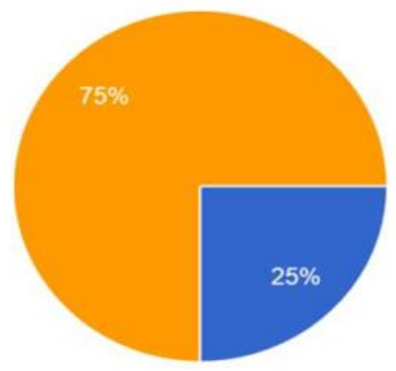

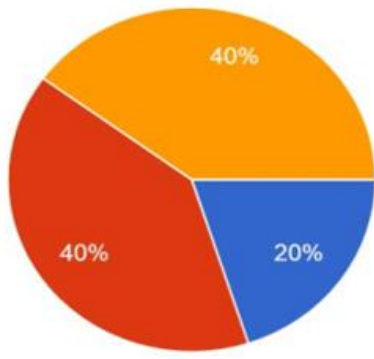

Fonte: Elaborado pelas autoras.
Muito difícil.

Difícil.

Mediano.

Fácil.

Muito fácil.

Este segundo gráfico aponta uma maior dificuldade para os alunos em relação ao segundo áudio da Prova 1. Não há nenhuma resposta no questionário que o considere fácil. Somando as duas turmas, a maioria dos alunos o consideraram difícil e muito difícil. Contudo, a categoria mediano prevalece como a mais escolhida.

\section{Turma $1-4$ respostas $\quad$ Turma $2-5$ respostas}

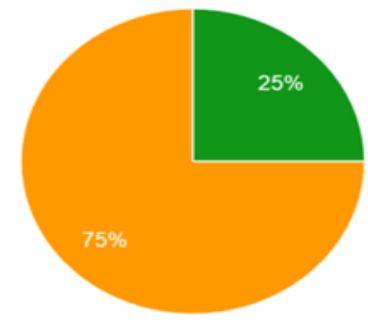

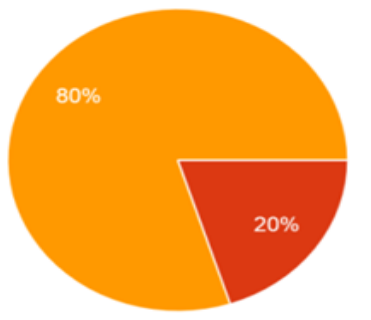

Fonte: Elaborado pelas autoras.
Muito difícil. Extremamente complicadas.

Difícil. Não estavam claras.

Mediano. Não vi grandes problemas em relação às perguntas

Fácil. Pude compreende-las tranquilamente.

Muito fácil. Extremamente claras.

O Gráfico 3 indica que a Prova 1 não apresenta questões que interfiram no desempenho da compreensão dos alunos em relação aos enunciados. Portanto, a partir das nossas análises e da verificação da percepção dos alunos, consideramos que a Prova 1 apresenta validade por servir adequadamente ao seu propósito nessa fase do curso 'Compreensão Oral: Palestras e Aulas B1/16h'.

\section{Prova 2}

Esta segunda prova segue a mesma estrutura da anterior, com 10 questões do tipo V/F. Contudo, utiliza apenas um áudio, do gênero palestra, com 06:44 minutos de duração, cujo título é Airport Design. No próximo quadro, temos uma visão detalhada da técnica mobilizada em cada questão da prova. 


\begin{tabular}{|c|c|c|}
\hline & Questão & Técnica \\
\hline \multirow{10}{*}{$\begin{array}{l}\text { Áudio } \\
\text { Airport design }\end{array}$} & 1 & Comparação e contraste \\
\hline & 2 & Detalhe \\
\hline & 3 & Causa e efeito \\
\hline & 4 & Detalhe \\
\hline & 5 & Causa e efeito \\
\hline & 6 & Causa e efeito \\
\hline & 7 & Detalhe \\
\hline & 8 & Causa e efeito \\
\hline & 9 & Exemplo \\
\hline & 10 & Comparação e contraste \\
\hline
\end{tabular}

Fonte: Elaborado pelas autoras.

Ao verificarmos o conteúdo e as técnicas trabalhadas nas aulas ministradas entre a Prova 1 e a Prova 2, temos o quadro a seguir no qual destacamos as técnicas contempladas na Prova 2.

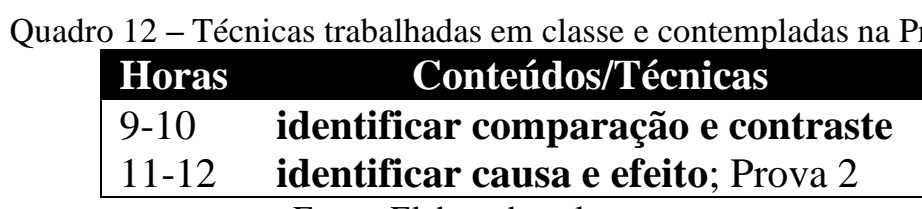

Fonte: Elaborado pelas autoras.

Nessa segunda prova, identificamos seis questões explícitas sobre duas técnicas das horas 9-12: Causa e efeito e Comparação, com predomínio da primeira. As outras perguntas têm foco direcionado aos detalhes da palestra sem um grande direcionamento aos conteúdos desenvolvidos. Nesse caso, poderíamos considerar que, em termos de validade de conteúdo, essa segunda prova é $60 \%$ válida, pois há questões que fogem do conteúdo trabalhado nas horas 9-12.

As percepções dos alunos quanto à dificuldade do áudio utilizado nessa prova e à clareza das questões são apresentadas nos gráficos que se seguem.

Gráfico 4 - Percepção dos alunos quanto à dificuldade do áudio da Prova 2.

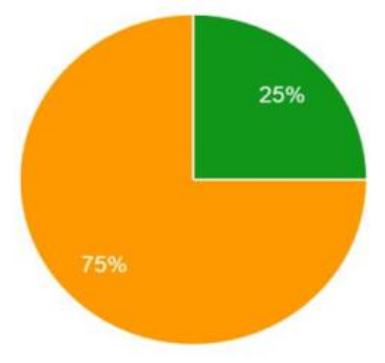

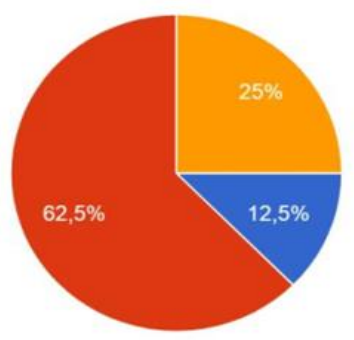

Fonte: Elaborado pelas autoras.
Muito difícil.

Difícil.

Mediano.

Fácil.

Muito fácil. 
Nota-se que o Gráfico 4 apresenta maior discrepância entre as duas turmas. Enquanto a primeira considerou o áudio majoritariamente mediano em termos de dificuldade, a maioria dos estudantes da segunda turma o considerou difícil.

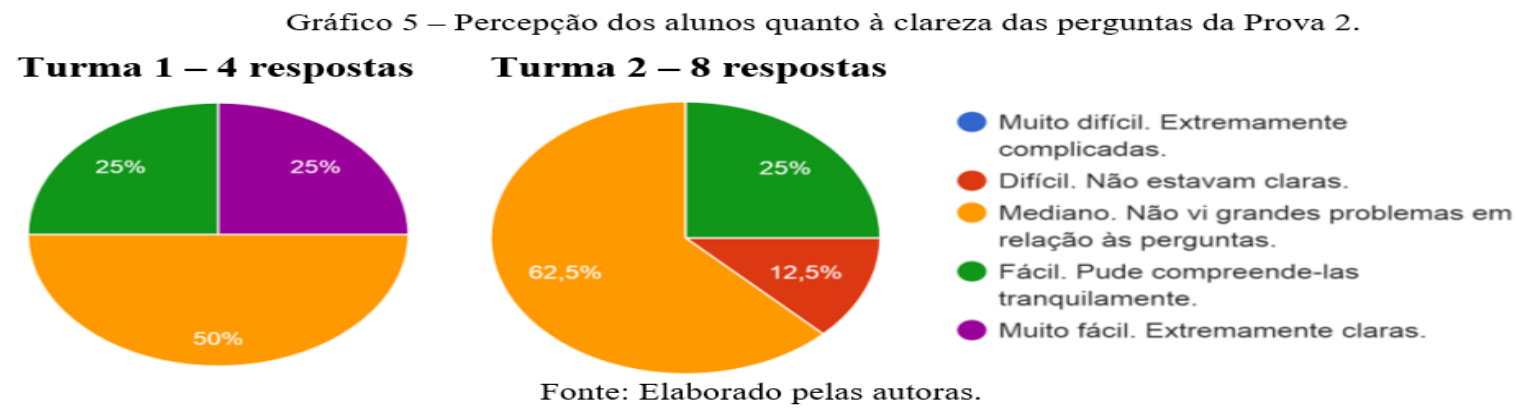

Neste gráfico, é possível notar que, novamente, não houve grandes problemas em relação às questões, pois a grande maioria dos alunos as considerou mediana. $\mathrm{O}$ fato de terem sido consideradas difícil por $12,5 \%$ dos alunos da segunda turma pode representar um alerta para uma possível revisão do enunciado das questões ou do seu nível de complexidade léxicosintático. Infelizmente, nossos dados não nos permitem aprofundar essa temática.

Prova 3

Esta prova segue a mesma estrutura da anterior: dez questões de V/F e um áudio do gênero palestra. Nesta prova, a palestra chama-se The history of jeans e o áudio tem 07:05 minutos de duração.

O Quadro seguinte mostra os conteúdos trabalhados individualmente em cada questão.

Quadro 13 - Técnicas mobilizadas pelas questões da Prova 3.

\begin{tabular}{|l|cl|}
\hline & Questão & Habilidade \\
& 1 & Detalhe/Explicação \\
2 & Detalhe/Explicação \\
3 & Detalhe/Explicação \\
Áudio & 4 & Detalhe/Explicação \\
The history of jeans & 5 & Comparação \\
& 6 & Comparação \\
& 7 & Detalhe/Explicação \\
& 8 & Detalhe/Explicação \\
& 9 & Detalhe/Explicação \\
& 10 & Detalhe/Explicação \\
\hline
\end{tabular}

Fonte: Elaborado pelas autoras.

Os conteúdos e técnicas trabalhados nas últimas horas do curso são: 
Quadro 14 - Técnicas trabalhadas em classe e contempladas na Prova 1.

\begin{tabular}{|cc|}
\hline Horas & Conteúdos/Técnicas \\
\hline $13-14$ & ouvindo argumentação. \\
\hline $15-16$ & ouvindo argumentação + prova 3. \\
\hline
\end{tabular}

A análise da validade de conteúdo dessa prova é mais complexa porque não há uma correspondência explícita entre as habilidades trabalhadas no plano de ensino e o que detectamos na análise das questões. Porém, se considerarmos que, no material dos alunos, eles são orientados a identificar argumentação através de 'informações de apoio', e que essas informações consistem em subtópicos como senso comum, exemplos, fatos e estatísticas, e opiniões de especialistas, e que, no decorrer da palestra The history of jeans, é possível identificar indícios (através de algumas expressões) de que esses subtópicos estão presentes, podemos dizer que há validade de conteúdo, mas ela não é explícita.

Contudo, nenhuma das questões de V/F estimula o estudante a identificar quais argumentos são reforçados por qual tipo de informação de apoio. Ao trabalhar as informações de suporte com as duas turmas do curso, foi possível perceber alguma dificuldade em diferenciar fatos e estatísticas de opiniões. Operacionalizar tal alinhamento na avaliação de maneira mais um pouco mais explícita seria um exercício interessante e talvez mais eficiente para o aprendizado dos alunos.

Nos gráficos a seguir, a percepção dos alunos.

Gráfico 6 - Percepção dos alunos quanto à dificuldade do áudio da Prova 3.

Turma $1-5$ respostas

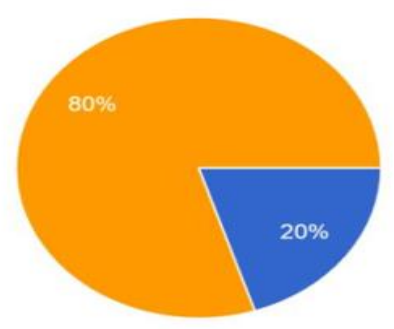

Turma $2-5$ respostas

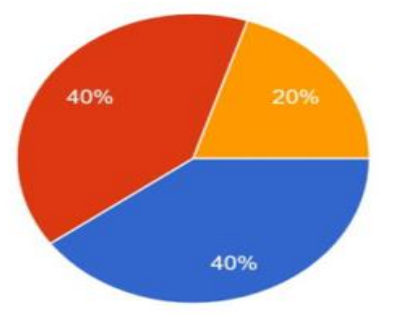

Fonte: Elaborado pelas autoras.

O Gráfico 6 apresenta uma grande diferença na percepção das duas turmas quanto à dificuldade do áudio da Prova 3. Enquanto a primeira turma, em sua maioria, considerou o áudio mediano, na segunda turma, $80 \%$ dos estudantes o apontaram como muito difícil e difícil. Neste caso, novamente temos um alerta que nos faz refletir sobre os motivos para essa percepção da segunda turma, que poderiam estar ligados a aspectos inerentes ao áudio 
propriamente dito, indicando possivelmente a necessidade de substituí-lo, ou a aspectos relativos às questões da prova e à não explicitação do construto sendo avaliado, como comentado anteriormente.

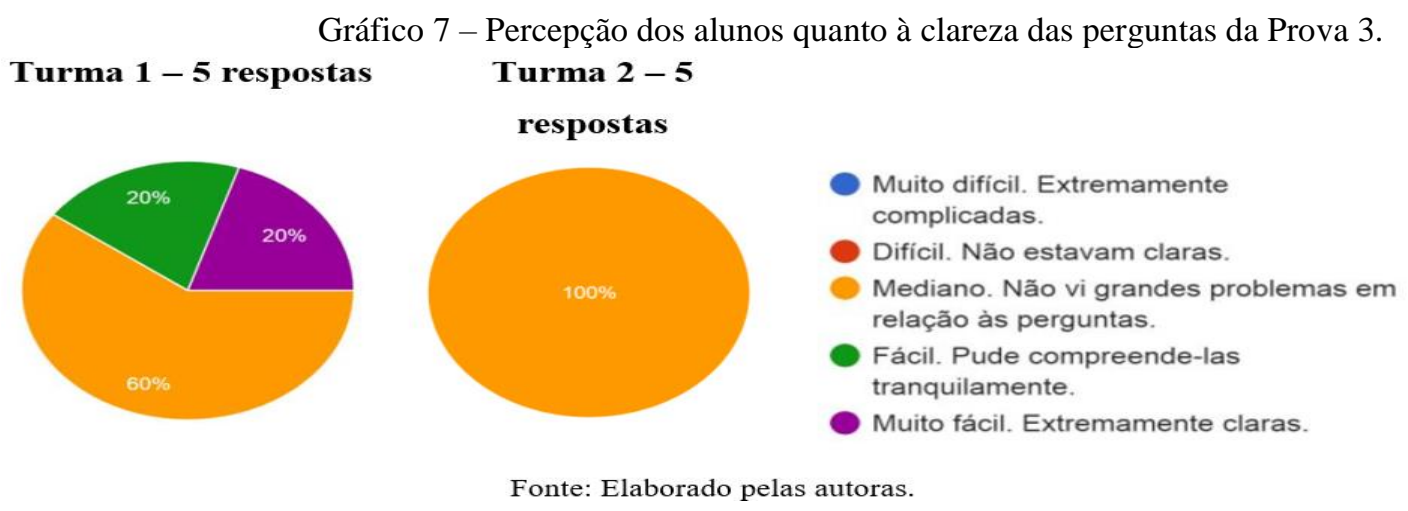

Em relação à clareza das perguntas, houve resultado similar às provas anteriores, com a maioria dos alunos considerando as questões medianas. Tal resultado nos leva a hipotetizar que a dificuldade reportada por $40 \%$ da Turma 2 em relação ao áudio esteja de fato relacionada ao áudio em si, e não às questões da Prova 3.

Antes de encerrarmos esta seção, algumas palavras sobre a confiabilidade e a praticalidade das provas. Com respeito à confiabilidade, julgamos que as três provas atenderam a essa condição quanto aos alunos - todos em sala de aula, sem nenhum problema contextual que mereça destaque, quanto à atribuição do escore - questões V/F com acertos calculados pelo próprio GoogleForms, e quanto ao teste propriamente dito - questões V/F previamente elaboradas por uma equipe. No entanto, houve um problema na aplicação da terceira prova que maculou sua confiabilidade: entre os minutos 2:40 e 3:40, o áudio começou a travar, impossibilitando os alunos de compreenderem o que a palestrante estava argumentando. Consequentemente, houve comprometimento da compreensão do restante da palestra. Na segunda oferta do curso, a atitude tomada pela aluna-professora para amenizar o problema foi pausar o áudio antes que começasse a travar e ler a transcrição do trecho com defeito para os alunos. Em seguida, o áudio continuou normalmente. Infelizmente, não houve tempo hábil para a substituição desse áudio e a elaboração de outra prova entre as turmas ministradas.

Por fim, cremos que, com relação à praticalidade, as três provas atendem aos quesitos de praticalidade quanto à elaboração, pois apresentam apenas um formato de questão que é relativamente fácil de elaborar e um número relativamente pequeno de questões; quanto 
à aplicação - feita por meio da disponibilização do link do GoogleForms no momento da prova, o qual era acessado pelos alunos com a utilização da rede Wifi da universidade; e quanto à correção, já que as respostas dos alunos ficavam automaticamente disponíveis à aluna-professora imediatamente após a aplicação das provas.

Concluimos, assim, esta seção, em que apresentamos nossas análises sobre a validade de conteúdo das três provas do curso 'Compreensão Oral: Palestras e Aulas B1/16h', acrescidas de comentários sobre confiabilidade e praticidade.

\section{Considerações finais}

Este artigo apresentou o relato de uma investigação que analisou a validade das provas aplicadas em um dos cursos oferecidos pelo IsF-Inglês no segundo semestre de 2019 chamado 'Compreensão Oral: Palestras e Aulas B1/16h', ministrado na Universidade de Brasília. Verificamos o alinhamento (total, parcial ou nulo) entre o plano de ensino e as três provas utilizadas no curso e as percepções dos alunos com relação à dificuldade dos áudios utilizados nessas provas e à clareza das questões, todas do tipo V/F.

Com base na análise do alinhamento e nas percepções dos alunos com relação à dificuldade dos áudios utilizados e da clareza das questões, verificamos que a primeira prova apresenta validade de conteúdo satisfatória, que seus dois áudios não foram considerados muito difíceis e que suas questões não causaram grandes problemas de compreensão. Com relação à segunda prova, a validade de conteúdo foi parcial (60\%), e o julgamento dos alunos quanto à dificuldade do áudio e à clareza das questões coincidiu com o feito para a primeira prova. Quanto à terceira prova, consideramos que há validade, embora tenha sido mais complexo verificar sua validade de conteúdo devido à ausência de correspondência explícita entre os itens do plano de ensino e a rubrica das questões. Com respeito à clareza das questões, houve a mesma percepção das provas anteriores. No entanto, chamou-nos a atenção o fato de que o áudio dessa prova foi aquele que mais alunos consideraram difícil, levandonos a refletir que os possíveis motivos para tal possam estar ligados ao próprio áudio (problema técnico ocorrido, à fala do palestrante ou ao tema da palestra), ou à ausência de correspondência explícita entre o trabalho feito em classe durante o curso e as questões dessa prova.

A nosso ver, uma reflexão relevante acerca das três provas como um todo é pensar sobre o fato delas seguirem a mesma estrutura e serem praticamente idênticas. Também é 
possível aplicar o pensamento de Brown (2004), que, inclusive, engloba os conceitos de validade e confiabilidade tratados anteriormente. O autor afirma que "[v]árias medidas sempre fornecerão uma avaliação mais confiável e válida do que uma única medida"9. Tentar outras formas de avaliar que englobem variados tipos de raciocínio pode ser um caminho para motivar os alunos, além de dar mais oportunidades para que demonstrem suas facilidades e/ou dificuldades em determinados tipos de prova.

\section{Referências Bibliográficas}

ABREU-E-LIMA, D.; MORAES FILHO, W. B.; NICOLAIDES, C. S.; QUEVEDOCAMARGO, G.; SANTOS, E. M. (Orgs.) Inglês sem Fronteiras: internacionalização da Educação Superior e formação de professores de língua estrangeira. Belo Horizonte: Editora UFMG, 2020.

BOHLKE, D.; LOCKWOOD, R. B. Skillful Listening \& Speaking 2. London: Macmillan, 2013.

BOYLE, M.; KISSLINGER, E. Skillful Listening \& Speaking 3. London: Macmillan, 2013.

BRAGA, J.C.F.; SOUZA, V.V.S; DELLAGNELO, A.C.K. Catálogo de cursos do IsF: unidade nacional. In: ABREU-E-LIMA, D.; MORAES FILHO, W. B.; NICOLAIDES, C. S.; QUEVEDO-CAMARGO, G.; SANTOS, E. M. (Orgs.) Sistemas de gestão e ações do Núcleo Gestor: a experiência do Programa Idiomas sem Fronteiras. Belo Horizonte: Editora UFMG, 2020.

BROWN, H. D. Language assessment: principles and classroom practices. 1st edition. New York: Pearson Education Ltd., 2004.

BROWN, H. D. Teaching by principles: an interactive approach to language pedagogy. 3rd edition. New York: Pearson Education Ltd., 2007.

CRAVEN, M.; SHERMAN, K. D. Q Skills for success: Listening and Speaking 3. Oxford: Oxford University Press, 2010.

FREIRE, R.; JONES, T. Q Skills for success: Listening and Speaking 4. 2nd Edition. Oxford: Oxford University Press, 2011.

GREEN, A. Exploring language assessment and testing. Oxon, UK: Routledge, 2014.

MARCONI, M.A.; LAKATOS, E.M. Fundamentos de metodologia científica. $5^{\text {a }}$ edição. São Paulo: Editora Atlas S.A., 2003.

\footnotetext{
${ }^{9}$ No original: Multiple measures will always give you a more reliable and valid assessment than a single measure (p.117).
} 
RETORTA, M. S.; MAROCHI, T. B. Avaliação em línguas estrangeiras: da teoria à prática. Curitiba: Editora CRV, 2018.

SCANLON, J. Q Skills for success: Listening and Speaking 1. Oxford: Oxford University Press, 2010.

UR, P. A course in language teaching: practice and theory. Cambridge: Cambridge University Press, 1996.

\section{Artigo recebido em: 16/06/2020 Artigo aprovado em: 06.07.2020}

